\title{
Photochromic intercalation compounds
}

Tomohiko OKADA1(tomohiko@shinshu-u.ac.jp),

Minoru SOHMIYA²(minoru.sohmiya@aoni.waseda.jp),

Makoto OGAWA ${ }^{2,3}$ (waseda.ogawa@gmail.com)

${ }^{1}$ Department of Chemistry and Material Engineering, Faculty of Engineering, Shinshu University, Wakasato

4-17-1, Nagano 380-8553

${ }^{2}$ Department of Earth Sciences, Waseda University, Nishiwaseda 1-6-1, Shinjuku-ku, Tokyo 169-8050, Japan

${ }^{3}$ Graduate School of Creative Science and Engineering, Waseda University, Nishiwaseda 1-6-1, Shinjuku-ku, Tokyo 169-8050, Japan

1. Introduction

2. General background

2.1 Photochromic reactions in solids

2.2 Host-guest systems

2.3. Forms of intercalation compounds

2.4. Photochromic reactions

3. Photochromic reactions of adsorbed dyes; fundamental studies

3.1 Spectroscopic and photochemical characteristics of the adsorbed photochromic dyes

3.2 Controlled reaction paths by host-guest interaction

4. Photo-responsive intercalation compounds

4.1 Photoinduced structural and morphological changes.

4.2. Photoinduced adsorption 
4.3. Photoresponse of magnetic properties

5 Photochromism based on photoinduced electron transfer

6. Conclusions and future perspectives

7. References

Abstract

Photochromism of intercalation compounds have been investigated so far. Starting from fundamental studies on the photochromic reactions of the dyes in the presence of layered materials, precise design of the nanostrctures of intercalation compounds toward controlled photochemical reactions and creation of novel photoresponsive supramolecular systems based on layered solids has been a topic of interests. Various layered materials with different surface chemistry have been used as hosts for the controlled orientation and aggregation of the intercalated dyes and the states of the intercalated guests affected photoresponses.

Molecular design of the photochromic dyes havs also been conuducted in order to organize them on layered solids with desired manner. On the other hand, layered solids with such functions as semiconducting and magnetic have been examined to host photochromic dyes for the photoresponsive changes in the materials' properties.

Keywords: Photochromism, Isomerization, Electron transfer, Intercalation, Host-guest hybrid, Photoregulation 


\section{Introduction}

Photochemical reactions in heterogeneous systems may differ significantly from analogous reactions in homogeneous solutions or in gas phases[1-6], and possible roles of the reaction media to control reaction rates and product selectivity has been recognized. In other words, one can tune the attractive properties, including photochemical reactions, by organizing functional species in nanospaces with appropriate geometry and chemical nature. Accordingly, photochemical reactions in various restricted geometries and chemical environments have been topics of interests of photochemistry and materials chemistry. Materials with nano-space have advantages in that the properties of the immobilized species can be discussed on the basis of their nanoscopic structures[7]. Their structure-property relationships will provide indispensable information on designing materials with controlled properties. Spectroscopic properties, which are very sensitive to the environment, of the immobilized species have given insights to the nanoscopic structures of the host-guest systems where conventional instrumental analysis does not have access[7-11]. By utilizing photoprocesses, one can obtain such information as distribution, orientation and mobility of the guest species.

Layered materials offer a two-dimensional expandable interlayer space for organizing guest species, among available ordered or constrained nano-environments [7, 12-20]. The study on the intercalation reactions has been motivated by the facts that the optical and electronic properties of both guest and host can be altered by the reactions[21-22]. If compared with other host-guest systems, the interlayer space of layered materials is characterized as the two dimensional expandable nanospace, whose geometry and chemical nature can be tailored by selecting and designing both the guests and hosts and also by co-adsorption. From X-ray diffraction studies, interlayer distances are measured and the orientation of the intercalated species are estimated based on their size and shape. Moreover, some materials have been processed into single crystals or oriented films, in which microscopic anisotropy can be converted into a macroscopic property[23]. The hierarchical anistropy achieved for the single crystal and oriented films, 
detailed characterization of the orientation of the adsorbed species have been done[24-25]. Such structural features make it possible to discuss the structure-property relationships in detail.

In this article, chemical and materials investigation regarding the photochromic reactions of intercalation compounds are summarized (Figure 1). Photochromism, which deals with photochemical reactions that are thermally or photochemically reversible (Scheme 1), has received considerable attention because of its actual and potential applications and for its paramount importance in biological phenomena[26-29]. Studies concerning photochromic reactions in solids have significance for practical applications such as optical recording. Accordingly, the interactions of photochromic dyes with layered solids has been investigated so far[30-42]. These studies have initially been done to characterize the interlayer nanospaces and the host-guest system, and then, to contribute to future practical applications of the intercalation compounds for optical recording and photoresponsive materials. The layered structures with the ability to accommodate a variety of guest species on the layer surface are very useful for organizing a variety of photoactive species to evaluate and to control photochromic reactions. Here, our attention will mainly be focused on the role of the nanostructures, which directly and in-direclty correlate the photochromic reactions.

Insert Figure 1 and Scheme 1.

\section{General back ground}

\subsection{Photochromic reactions in solids}

Photochrmoic reaction of dyes in solid matrices have been reported so far[29, 31]. In order to evaluate the photochemical reactions, solids with photochemically inert and optically transparent in UV and visible light are useful. Therefore, various polymers and silica gels have been used[26, 43-46]. The optical transparency has been achieved for amorphous systems, so that, in general, the concentration of the dye is low, and the orientation and distribution of the photochromic moiety are random. In addition to the systems based 
on photochrmoic compounds in such transparent solid matrices as polymers and silicas, vairous supramolecular systems have been utilized in order to organize photochrmoic moeity in a controlled manner, Zeolites and mesoporous materials have been used as matrices for constructing photofunctional hybrids[1-2, 4-5, 47-51]. Chemical interactions between matrices and photochrmoic dyes have been designed to construct host-guest photochrmoic materials[52-55]. As a recent example of solid-state photochromic host guest system, which is relevant to the intercalation compouds, a metal-organic framework (MOF; or a porous coordination polymer PCP) with azobenzene group introduced to the organic linker has been developed for reversible change in $\mathrm{CO}_{2}$ uptake upon external stimuli[56]. The positional changes of the dangling benzene group in cubic cavity of a MOF upon reversible trans-to-cis photoisomerization have been a possible reason to the increased and decreased $\mathrm{CO}_{2}$ uptake. Photoresponsive adsorption of $\mathrm{N}_{2}$ has also been realized by photoisomerization of azobenzene group in the material[57].

Photochromic moieties have been covalently immobilized into organic supramolecular systems such as surfactant assemblies and polymers. Surfactant assemblies often take membrane like two dimensional structures, therefore relevant to layered compounds and their intercalation compounds[6]. Chemical and structural stability, mechanical property, optical quality, prepaparation and processing of different supramolecular systems should be discussed for practical applications. In order to achieve photoresponsive materials, the introduction of photochromic moiety into microheterogeneous systems have also been conducted extensively. The supramolecular photochemistry concepts have also been motivated to biologial application of photochemical switches[26]. Nanoparticles of layered solids can be a possible candidate for such purposes.

\subsection{Host-guest systems}

Smectite is a group of 2:1 clay minerals consisting of negatively charged silicate layers and readily exchangeable interlayer cations[16, 24, 58, 59]. Isomorphous substitution of framework metal cations with 
similar size and lower valency generates a net negative charge for layers, and to compensate for the negative charge, such metal cations as sodium and calcium occupy the interlayer space. The amount as well as the site of the isomorphous substitution influences the surface and colloidal properties of smectites. Impurities present both within the structure and on the partcle surface, and their amountsvaried depending on the source of the clay minerals. Synthetic analogues of smectites, i.e. hectorite (Laponite, Rockwood Ind. Co.)[60], saponite (Sumecton SA, Kunimine Ind. Co.)[61], and swelling mica (sodium-fluor-tetrasilicic mica, TSM, Topy Ind. Co.)[62, 63], have advantages for the photochemical studies since natural clay minerals contain impurities, which gave colored clays. Synthetic analogues of smectite have been prepared in laboratory and used for the adsorption of dyes[19, 64-67].

The mechanism of the intercalation for smectite can be classified into two[16, 24]; the cation exchange with interlayer exchangeable cations and the adsorption of polar molecules by ion-dipole interactions with interlayer cations and/or hydrogen bonding with the surface oxygen atom of the silicate sheets. One of the characteristic features of smectites is the possible surface modification. Nanoporous pillared smectites have been obtained using inorganic particles and small organic cations as pillars $[68,69]$ and, on the contrary, organophilic modification has been conducted by cation exchange with cationic surfactants of various structures[70-75] (Figure 2).

Insert Figure 2.

Besides smectites, a large variety of layered solids with the ability to accommodate guest species in the interlayer space are available[7, 15, 17, 21,22]. Layered alkali silicates are capable of incorporating guest species (organoammonium ions and polar molecules) in the interlayer space to form intercalation compounds[72, 76-79]. Organosilane grafted derivatives have been obtained previously[80-91]. Compared with smectites, the series of layered alkali silicates possess such useful properties for organizing 
guest species as the high layer charge density and well defined particle morphology. Metal phosphates and phosphonates, and layered transition metal oxides have also been used for constructing photochromic intercalation compounds[89-93].

Due to the variation of the layer charge density, particle morphology, and electronic properties, host-guest systems with unique microstructures and properties have been obtained. On the other hand, the intercalation of guest species is not as easy as it is for smectities. In order to introduce bulky organic species in the interlayer spaces with designed manners, organoammonium-exchanged forms, which are prepared by conventional ion exchange reactions in aqueous media, have been used as the intermediates[25, 94-96].

Layered double hydroxides (LDHs) are composed of positively charged brucite-type layers of mixed-metal hydroxides and exchangeable anions located at the interlayer spaces, which compensate for the positive charge of the brucite-type layers[97-101]. Due to the structural and compositional characteristics, the application of LDHs in such areas as adsorpion, catalyst, medical and biochemical application, has been proposed so far[100, 101]. The chemical composition of the LDHs is generally expressed as $\left[\mathrm{M}(\mathrm{II}) 1-\mathrm{x} \mathrm{M}^{\prime}(\mathrm{III}) \mathrm{X}(\mathrm{OH}) 2\right]\left[\mathrm{A}^{\mathrm{n}-} \mathrm{x} / \mathrm{n}\right]^{\mathrm{X}-}{ }^{-}$where $\mathrm{M}(\mathrm{II})=\mathrm{Mg}, \mathrm{Co}, \mathrm{Ni}$, etc., $\mathrm{M}(\mathrm{III})=\mathrm{Al}, \mathrm{Cr}$, Fe, etc., and $\mathrm{A}$ is an interlayer anion such as $\mathrm{CO}_{3}{ }^{2-}$ and $\mathrm{Cl}^{-}$. Anionic species have been introduced into the interlayer spaces of LDHs by three methods. Anion exchange reactions using an aqueous solution of guest species has been investigated widely. Compared with the cation exchange of smectites, the ion exchange reaction for LDHs is more difficult because of their high selectivity to carbonate anions. Therefore, $\mathrm{CO}_{2}$ should be excluded during the sample preparation. Intercalation compounds have also been prepared via direct synthesis in which a LDH phase precipitates in the presence of a guest species[102]. The reaction of a mixed-metal oxide solid solution, which was obtained by the thermal decomposition of LDH-carbonate, with an aqueous solution of guest species results in the formation of LDH intercalation compound [Reconstruction method][103]. 
In addition to the crystalline structures, the particle size and its distributions of layered solids are key issues in order to achieve optimum performance of layered solids and their intercalates, accordingly, attention has been paid for the powder morphology[104]. Recently, mono-dispersed particles of LDHs has been obtained[105-108]. The effects of synthetic temperature on particle size of layered transition metal oxides, which affected the photocatalytic ability, have also been reported recently[109, 110].

Thanks to the variation of availabe layered solids with designable chemical nature, one can investigate photochromic reactions of cationic, anionic and nonionic photochromoic molecular species. The location, distribution, and orientation of the photochromic moieties can be designed by selecting host and host-guest complexation, in order to control the photochromic reactions.

\subsection{Forms of intercalation compounds}

For the evaluation of the photoprocesses, samples have been obtained as powders, suspensions and thin films. One of the most unique and attractive properties of smectites is their spontaneous swelling in water. By dispersing in water, smectites form a stable thixotropic gel or suspension. The careful preparation of suspension occasionally led liquid crystalline phases for smectites, layered transition metal oxides, arsenate and so on[111-116]. One of the advantages of using exfoliated layered solids (nanosheet) suspension if compared with microheterogeneous systems composed of surfactant and polymer is the stable layered structures in the wide range of temperature, composition and solvents. In microheterogeneous systems composed of soluble surfactants and polymers, the nanostructures vary significantly depending on the experimental conditions.

When the suspension is evaporated on a flat plate, platy particles pile up with their $a b$ plane parallel to the substrate to form a film[117-119]. The preparation of thin films by the Langmuir-Blodgett technique from exfoliated platelets of clays has also been reported[120-122]. Inorganic-organic multilayered films have also been prepared via alternate adsorption of a cationic species and an anionic sheet of an exfoliated 
layered solid (Layer-by-Layer deposition technique, hereafter abbreviated as LbL technique)[123-130]. In order to apply LbL for the fabrication of thin films, swelling of layered solids into nano dimension is a basic prerequisite. Therefore, the exfoliation of various layered solids has been a topic of active research during thess two decades after the successful preparation of so-called nanosheet suspension and thin films formation[126, 131-134]. The exfoliation and the film preparation will be described in other article of this volume by Sasaki et al.

\subsection{Photochromic reactions}

"E-Z" isomerization of azobenzenes, cyclization of spiropyranes and spirooxazines, cycloaddition of stilbenes and reduction of viologen have been investigated so far. The involved chemical reactions are shown in following schemes.

\section{Photochrmoic reaction of adsorbed dyes; fundamental studies}

3.1 Spectroscopic and photochemical characteristics of the adsorbed photochrmoic dyes

Amphiphilic cationic azobenzene derivatives (Scheme 2a and 2b) have been intercalated into layered silicates (magadiite and montmorillonite)[135-138]. The dye orientation in the interlayer spaces has been discussed from the spectral shifts and the gallery heights of the products. The intermolecular interactions of chromophores give aggregated states and the dye-dye interactions causes both bathochromic and hypsochromic spectral shifts depending on the nanostructures of aggregates[139]. The spectral shifts reflect the orientation of the dipoles in the aggregates; smaller spectral red shifts are expected for the aggregates with larger tilt angles of the dipoles. Depending on the layer charge density (cation exchange capacity; CEC) of host materials and the molecular structures of the amphiphilic azo dyes, aggregates ( $J$ - and $H$-aggregates) with different microstructures (tilt angle) formed in the interlayer spaces of layered silicates. 
Insert Scheme 2.

The intercalation of ionic photochromic dyes into the interlayer space of ion exchangeable layered solids has been investigated extensively[30, 140-142]. Katsuhiko Takagi et al. reported the intercalation of 1',3',3'-trimethylspiro[2H-1-benzopyran-2,2'-indoline](H-SP) and its 6-nitro ( $\mathrm{NO}_{2}$-SP) and 6-nitro-8-(pyridinium)-methyl ( $\left.\mathrm{Py}^{+}-\mathrm{SP}\right)$ derivatives into montmorillonite, and their photochromic behavior has been studied for colloidal suspension[32]. The effects of the intercalation on the rate of thermal coloration and decoloration have been compared with those in other systems such as colloidal silica, aqueous micellar solution of hexadecyltrimethylammonium bromide $\left(\mathrm{C}_{16} 3 \mathrm{C}_{1} \mathrm{~N}^{+} \mathrm{Br}\right)$ or sodium dodecylsulfate (SDS). Besides the results on the photochemical studies, one of the advantages of using layered solids is the robust layered structure existing in the wide range of temperature, composition and solvents. In microheterogeneous systems composed of soluble surfactants and polymers, the nanostructures vary significantly depending on the experimental conditions.

$\mathrm{Py}^{+}$-SP was intercalated into montmorillonite quantitatively as an equilibrium mixture with the corresponding merocyanine (MC) with the ratio of $\mathrm{Py}^{+}-\mathrm{SP}: \mathrm{Py}{ }^{+}-\mathrm{MC}$ of 35:65 and exhibited reverse photochromism. It is known that thermal equilibria between SP and MC are dependent on the polarity of the molecular surroundings; MC becomes the major product under the increased polarity environments. The reverse photochromism observed for the montmorillonite systems has been explained in terms of the polar nature of the interlayer space of montmorillonite. The thermal isomerization of $\mathrm{Py}^{+}-\mathrm{SP}$ intercalated in aqueous colloidal montmorillonite suspension exhibited a linear combination of two components of first order kinetics, indicating the presence of two different states of the intercalated $\mathrm{Py}^{+}-\mathrm{SP}$; one is molecularly separated species and the other is aggregated species.

In contrast, a preferential adsorption as $\mathrm{SP}$ was observed when and $\mathrm{NO}_{2}-\mathrm{SP}$. Normal photochromism has been observed in these systems. Single first-order kinetic has been observed for the 
$\mathrm{Py}^{+}-\mathrm{SP}-\mathrm{C}_{16} 3 \mathrm{C}_{1} \mathrm{~N}^{+}$-montmorillonite. The effects of the co-adsorbing $\mathrm{C}_{16} 3 \mathrm{C}_{1} \mathrm{~N}^{+}$on the photochromic behavior showed that the $\mathrm{C}_{16} 3 \mathrm{C}_{1} \mathrm{~N}^{+}$surrounds $\mathrm{Py}^{+}-\mathrm{SP}$ to create a hydrophobic environment for each Py+-SP molecule.

The photochromism of a cationic diarylethene, 1,2-bis(2-methyl-3-thiophenyl)perfluorocyclo-pentene bearing two pyridinium substituents at each thiophenyl ring, intercalated in montmorillonite was reported so far[143]. The product was prepared as oriented films by casting and the dye orientation was deduced from the basal spacing and spectroscopic behavior, which was determined by using polarized light. The photochromic reaction was efficient and smooth, while the efficiency decreased upon repeated irradiation. The decrease was attributed to the formation of photo-inactive species (degradation). The degradation was successfully suppressed by the co-adsorption of dodecylpyridinium cations with the cationic diarylethene.

Intercalation of another cationic diarylethene, 1,2-bis(2'-methyl-5'-(1''-methyl-3''-pyridinio)thiophen-3'-yl)-3,3,4,4,5,5-hexafluorocyclopentene (1, the molecular structure is shown in Figure 3a), into montmorillonite was reported[33, 144]. As schematically shown in Figure 3b, from XRD and UV-Vis polarized spectroscopy, the cationic diarlyethene $\mathbf{1}$ was shown to be anistropically accommodated with DMF in a gelatin film involving the dye-montmorillonite hybrid,. The photochemical interconversion between a colorless $\mathbf{1}$ and blue colored $\mathbf{2}$ was achieved with good repeatability (Figures 3a and 3c). The interconversion was also observed for diarylethene, which was covalently immobilized to the surface silanol groups on magadiite[145, 146].

Insert Figure 3.

On the other hand, nonionic photochrmoic dyes have been intercalated to the long chain organoammonium-modified silicates[36-37, 41-42, 135, 147]. The role of the surfactant is not only for 
producing hydrophobic interlayer spaces, but also for controlling the states of the adsorbed dyes. Seki and Ichimura have investigated the thermal isomerization kinetics of photoinduced merocyanine (MC) to spiropyran (SP) in solid films having multi-bilayer structures, which consists of ion complexes between cationic bilayer forming amphiphile (dioctadecyldimethylammonium cation, abbreviated as $2 \mathrm{C}_{18} 2 \mathrm{C}_{1} \mathrm{~N}^{+}$) and polyanions (montmorillonite and poly(styrene sulfonate), abbreviated as PSS)[34].

1,3,3-Trimethyl-6'-nitrospiro[indoline-2,2'-2'H-benzopyran](SP) was incorporated into the thin films of the polyion complexes, which were prepared by casting the chloroform solution or suspension of the polyion complexes.

X-Ray diffraction studies showed that the cast films were composed of a multi-bilayer structure whose lamellar plane was oriented parallel to the film surface. Endothermic reactions were observed in the DSC (differential scanning calorimetry) curves of the films to show the phase transition at the temperatures of 54.5 and $48.5^{\circ} \mathrm{C}$ for the $2 \mathrm{C}_{18} 2 \mathrm{C}_{1} \mathrm{~N}^{+}$-montmorillonite and $2 \mathrm{C}_{18} 2 \mathrm{C}_{1} \mathrm{~N}^{+}$-PSS films, respectively. Both DSC and X-ray diffraction results indicated that the $2 \mathrm{C}_{18} 2 \mathrm{C}_{1} \mathrm{~N}^{+}$-montmorillonite film had a more ordered structure than $2 \mathrm{C}_{1} 82 \mathrm{C}_{1} \mathrm{~N}^{+}-\mathrm{PSS}$ film. Annealing the film at $60-70^{\circ} \mathrm{C}$ at the relative humidity of ca. $100 \%$ for a few hours resulted in the improved ordering of $2 \mathrm{C}_{18} 2 \mathrm{C}_{1} \mathrm{~N}^{+}$-PSS film, and the photochromic behavior was investigated for the annealed films. The difference in the film structure influenced the kinetics of the thermal decay of MC embedded in the films. The incorporated SP exhibited photochromism in both of the immobilized bilayer complexes with montmorillonite and PSS. The decoloration reaction rate was dependent on the mobility of the surroundings and, in polymer matrices, was influenced by the glass transition. It was found that the reaction rates abruptly increased near the gel to liquid-crystal phase-transition temperature $\left(54^{\circ} \mathrm{C}\right)$ of the immobilized bilayer due to increased matrix mobility in this system. The film prepared with montmorillonite gave more homogeneous reaction environments for the chromophore than those with PSS. This led to the drastic changes in the reaction rate at the crystal to liquid-crystal phase transition of the bilayer, showing the effect of the phase transition of bilayers immobilized 
on layered solids to be more pronounced than that of the transition of bilayers immobilized on amorphous polymers.

The formation of $H$ (parallel type) and $J$ (head-to-tail type) aggregates of photo-merocyanines upon adsorption in didodecyldimethylammonium $\left(2 \mathrm{C}_{12} 2 \mathrm{C}_{1} \mathrm{~N}^{+}\right)$-montmorillonite has been suggested for a series of 1'-alkyl-3',3'-dimethyl-6-nitro-8-alkanoyloxymethylspiro(2H-1-benzopyran-2,2'-indoline) derivatives with different length of alkylchains[35]. A cast film consisting of the SP incorporated in the $2 \mathrm{C}_{12} 2 \mathrm{C}_{1} \mathrm{~N}^{+}$-montmorillonite was prepared on a glass plate by slowly evaporating the suspension of the SP and $2 \mathrm{C} 122 \mathrm{C}_{1}{ }^{+}$-montmorillonite. When longer alkylchains were introduced, new very sharp absorption peak appeared at around $500 \mathrm{~nm}$ upon UV light irradiation in addition to the absorption at $570 \mathrm{~nm}$ due to the monomeric photomerocyanine (abbreviated as PMC). New sharp absorption bands appeared at a longer wavelength region (around $610 \mathrm{~nm}$ ) when SPs bearing longer alkylchains were exposed to UV light. These new absorption bands are attributed to aggregates of PMCs which are reported to form occasionally in organized molecular assemblies[35]. The absorption bands at around 500 and $610 \mathrm{~nm}$ have been ascribed to $H$ and $J$ aggregates of PMC, respectively. A high activation energy and highly positive activation entropy for $J$ and $H$ aggregates of PMCs, which directly correlate with the thermal stability of these aggregates (which led the slow decoloration), have been observed. Thus, the the kinetic of the thermal decoloration of the MCs were determined by the aggregation, which was controlled by the host-guest inteactions. From this viewpoint, layerd materials are quite useful as matrices of dye and dye aggregate (aggregation and isolation) because of the expandable interlayer space (geometrically adaptable size for both isolated molecules and dye aggregates) and the variable layer charge density, which directly correlates with the intermolecular distantce between adjacent ionic guest species.

Photochemical trans-to-cis isomerization of azobenzenes intercalated in the hydrophobic interlayer space of alkylammonium-montmorillonite and TSMs has also been investigated [36,37, 41]. Intercalation compounds were obtained by a solid-solid reaction between the organophilic-hosts and nonionic azobenzene. 
The intercalated azobenzene showed reversible trans-to-cis photoisomerization upon UV irradiation and cis-to-trans isomerization by subsequent thermal treatment (or visible light irradiation). The hydrophobic interlayer space of the alkylammonium-smectites serves as reaction media for the immobilization and efficient photochemical isomerization of the azo dye. The degree of the isomerization at the photostationary states varied, suggesting the possible design toward optimized photochemical reactions by selecting host-guest systems.

For detailed evaluation of the photochemical reactions, dialkyldimethylammonium $\left(2 \mathrm{C}_{\mathrm{n}} 2 \mathrm{C}_{1} \mathrm{~N}^{+}\right)$-TSM-azobenzene intercalation compounds were fabricated as films by casting the suspension of the $2 \mathrm{C}_{n} 2 \mathrm{C}_{1} \mathrm{~N}^{+}-\mathrm{TSM}$ and azobenzene on a flat substrate[37]. The intercalated azobenzene also exhibits reversible photochromic reactions. The fraction of the photochemically formed cis-isomer in photostationary states depends on the reaction temperature(Figure 4A, the experimental setup is shown in Figure 4B), suggesting that a change in the states of the interlayer $2 \mathrm{C}_{2} 2 \mathrm{C}_{1} \mathrm{~N}^{+}$occurs. The phase transition temperatures estimated from the photochemistry of azobenzene were in good agreement with the values determined by other techniques[34, 148, 149].

\section{Insert Figure 4.}

The $d$ values for the $2 \mathrm{C}_{\mathrm{n}} 2 \mathrm{C}_{1} \mathrm{~N}^{+}$-smectites varied $[34,37,148-150]$ and the difference in the basal spacings corresponds to the difference in the orientation of the alkylchains. It has been known that excess guest species can be accommodated in the interlayer spaces of smectites as a salt, and this phenomenon is refereed to as "intersalation". The large $d$ values reported in the literature may be due to the intersalation as well as the difference in the surface layer charge density.

The introduction of retinal, which is the chromophore of rhodopsin, into a surfactant (dimethyloctadecylammonium) modified clay was investigated in order to mimic the properties of 
rhodopsin[38, 39]. The spectroscopic and photochemical properties of retinal in vitro are of interest in studying the primary chemical process of vision and in developing novel photoresponsive materials. The modified clay interlayer offers environments for retinal similar to rhodopsin in two respects; color regulation and efficient isomerization at a cryogenic temperature. Protein environments have the ability to tune the color of retinal Shiff bases; however, the color regulation in artificial systems was not satisfactory. In rhodopsins, a retinal molecule forms a Schiff base linkage with a lysine residue and the retinal Shiff base is protonated. It was proposed that a proton was supplied from dimethyloctadecylammonium to retinal Shiff base. The trans-to-cis isomerization of a protonated retinal Shiff base occurs even at $77 \mathrm{~K}$ as revealed by visible and infrared spectroscopy. On the other hand, azobenzene isomerization in dialkyldimethylammonium-TSM was reported to be suppressed at lower temperature. The efficient isomerization of retinal at $77 \mathrm{~K}$ was worth mentioning as a mimic of the primary photochemical reaction in rhodopsin. The difference is worth investigating systematically using similar materials (clay minerals, surfactants and dyes). The adsorption of retinal onto smectites with different origin was examined to find the color development of retinal depends on the nature of clay mineals[40]. The isomerization of the retinal adsorbed on various clay minerals is worth investigating further[40].

Amphiphilic cationic azobenzene derivatives (Scheme $2 \mathrm{a}$ and $2 \mathrm{~b}$ ) have been intercalated into the layered silicates magadiite and montmorillonite to show the controlled orientation by the host-guest interactions[135-139]. Layer charge density determine the orientation (tilt angle) of the intercalated dye when quantitative ion exchange was achieved. The azobenzene chromophore photoisomerized effectively in the interlayer space of silicates, despite the fact that the azobenzene chromophore is aggregated there. These unique characteristic have been used for the construction of photoresponsive intercalation compounds, which will be described in the following section of this article. 
The interlayer spaces of clay minerals have been shown to provide a stable and characteristic reaction field suitable for streochemically controlled photochemical reactions. Regioselective photocycloaddition of stilbazolium cations, intercalated in the interlayer space of saponite, have been reported[147, 151, 156]. There are four possible photochemical reaction paths of the stilbazolium ion (Fig. 5 (a)). Upon irradiation of UV light to a stilbazolium-saponite suspension, syn-head-to-tail dimers (2, in Fig. 5 (a)) were predominantly formed at the expense of cis-to-trans isomerization (4, in Fig. 5 (a)), which is a predominate path in homogeneous solution. The selective formation of head-to-tail dimers suggests that the intercalation occurs in an anti-parallel fashion, as shown in Fig. 5(b). Since the dimer yields were only slightly dependent on the loading amount, stilbazolium ions were adsorbed inhomogeneously and form aggregates with anti-parallel alternative orientation even at very low loading (1\% of C.E.C.) This aggregation was supported by the fluorescence spectrum of the dye adsorbed on saponite, in which excimer fluorescence was observed at 490-515 $\mathrm{nm}$ at the expense of the monomer fluorescence at ca. $385-450 \mathrm{~nm}$. The selective formation of syn head-to-tail dimers indicates the formation of the aggregates with anti-parallel alternative orientation owing to hydrophobic interaction between the adsorbate ions.

The aggregation state of $\gamma$-stilbazolium [4-(2-phenylvinyl)pyridinium] ion on saponite was changed by the coadsorption of alkylammonium ions $\left(\mathrm{C}_{n} \mathrm{~N}^{+}\right)$; where $\mathrm{n}$ indicate the carbon numer in the alkylchain [153]. Fig.5(c) shows the effect of $\mathrm{C}_{8} \mathrm{~N}^{+}$on photoreactivity of the pre-intercalated stilbazolium ions on the synthetic saponite. On co-adsorbing $\mathrm{C}_{\mathrm{n}} \mathrm{N}^{+}$with the alkyl group longer than the stilbazolium ion, the major photo chemical reaction was changed from cyclodimerization to trans-to-cis isomerization and the excimer emission of the intercalated stilbazolium ions was dramatically reduced.

Insert Figure 5. 
Photochemical cycloaddition for several unsaturated carboxylates has been studied in the presence of a layered double hydroxide, hydrotalcite $[154,156,157]$. In addition to the anti-parallel packing of the guest, the intermolecular distances of two double bonds of adjacent carboxylates were found to affect the stereoselectivity of the photochemical reactions. While cinnamate yielded head-to-head dimers exclusively, stilbenecaroboxylates gave a significant amount of head-to-tail dimer in addition to a head-to-head dimer. This difference was explained by molecular packing of the dye anions in the interlayer space of hydrotalcite. Being similar to the effects of the organoammonium ions on the photochemistry of stilbazolium ions in smectite as mentioned before [153], the addition of $p$-phenethylbenzoate, a photochemically inactive co-adsorbate, affected significantly the product distribution of $p$-(2-phenylethenyl)benzoate upon irradiation. The series of pioneering investigations on the roles of host-guest interactions on the slectivity of the reactions paths shows that the organization of organic species into the interlayer space of layered materials is a way of crystal engineering in which reaction selectivity can be determined. In other words, the relation between the selectivity of reactions and the interlayer spacing is a method of probing the orientation and aggregation of the intercalated species. Thus, the photochemical reactions of the adsorbed photochromic dyes are useful for the evaluation of the orientation and packing in the interlayer space as well as for controlling the reaction paths and efficiiency. More recently, Shinsuke Takagi and his co-workers reported the photochemical behaviors of a dicationic azobenzene on saponite and in aqueous solution to find an important role of the saponite surface to control the relative stability of two isomers (trans and cis-forms). The quantum yield of trans-to-cis photoisomerization of the azo dye cation on the saponite was much smaller than that in water, while cis-to-trans isomerization was accelerated. Almost $100 \%$ trans-isomer was successfully obtained after the visible light irradiation thanks to the interactions bewteen the dye and saponite surface [142].

3.3 Some relevant studies on the optical application of intercalation compounds 
Photochemical hole burning (PHB) is another phenomera relevant to the photochromism, which is a quite sensitive tool to probe the host-guest interactions. $\mathrm{PHB}$ is the site-selective and persistent photobleaching of an inhomogeneously broadened absorption band, induced by resonant laser light irradiation at cryogenic temperatures [158]. PHB has attracted attention due in part to its possible applicability to high-density frequency domain optical storage, in which more than $10^{3}$ times more storage density than present optical disk systems would in principle be available. Since the phenomena occurred at cryogenic temperature using laser, naked eye observation of the color change is almost impossible. A search for new materials has been done because the hole formation processes depend significantly on the nature of host-guest systems. For the PHB materials, host-guest system is essential. Since hole formation depends significantly on the structures of host-guest systems, it can be used as high resolution solid-state spectroscopy. PHB reaction of intercalation compounds using synthetic saponite and 1,4-dihydroxyanthraquinone (abbreviated as DAQ) and cationic porphines, both of which are typical PHB dyes, has been reported[159, 160].

We have prepared the TMA-saponite-DAQ intercalation compound and investigated its PHB reaction to show the merits of nanoporous saponite. The PHB reaction of DAQ is 1 due to the breakage of internal hydrogen bond(s) and the subsequent formation of external hydrogen bond(s) to proton acceptor(s) within a matrix. A molecularly isolated chromophore is another basic prerequisite for efficient PHB materials, in order to avoid line broadening due to energy transfer. For this purpose, saponite was modified by tetramethylammonium (abbreviated as TMA) ions to obtain independent micropores in which a DAQ molecule was incorporated without aggregation. Taking into account the molecular size and shape of DAQ and the geometry of the micropore of TMA-saponite, DAQ was intercalated with the molecular plane nearly perpendicular to the silicate sheet.

A persistent spectral zero-phonon hole was obtained at liquid helium temperatures by $\mathrm{Kr}^{+}$laser light irradiation (520.8 nm). In spite of the high concentration of DAQ (ca. $1.5 \mathrm{~mol} \mathrm{~kg}^{-1}$ ), a narrow hole with an 
initial width of $0.25 \mathrm{~cm}^{-1}$ (at $4.6 \mathrm{~K}$ ) was obtained. The width was narrower than those (e.g. $0.4 \sim 0.8 \mathrm{~cm}^{-1}$ ) of DAQ doped in ordinary polymers and organic glasses (e.g. PMMA, ethanol/methanol mixed glass) obtained under similar experimental conditions. Narrow line width is desirable for the optical recording application, since the number of holes to be made in a inhomogeneously broadened band increases for narrowr hole. The width is related mainly to the dephasing but contributions from spectral diffusion cannot be neglected. On the other hand, a broad pseudo-phonon sidehole, whose shift from the zero-phonon hole is $25 \mathrm{~cm}^{-1}$, appears only after irradiation stronger than $1500 \mathrm{~mJ} \mathrm{~cm}^{-2}$. The burning efficiency was high, being similar to or higher than the typical one observed in ordinary dye-dispersed in amorphous solids. The microporous structure of the TMA-saponite intercalation compound therefore apparently leads to some desirable characteristics regarding hole formation.

Nonliner optics (NLO) of organic compounds is another relevant phenomenon where nanostructures of intercalation compounds desgined by host-guest interactions. In the NLO application, photochemical reactions should be avoided to achieve durable performances. Nonlinear optics comprises the interaction of light with matter to produce a new light field that is different in wavelength or phase[161, 162]. Examples of nonlinear optical phenomena are the ability to alter the frequency (or wavelength) of light and to amplify one source of light with another, switch it, or alter its transmission characteristics throughout the medium, depending on its intensity. Since nonlinear optical processes provide key functions for photonics, activity in many laboratories has been directed toward understanding and enhancing secondand third-order nonlinear effects. Second harmonic generation (SHG) is a nonlinear optical process that converts an input optical wave into an outwave of twice the input frequency. Large molecular hyper polarizabilities of certain organic materials lead to anomalously large optical nonlinearities. Research efforts had been done toward (a) identifying new molecules possessing large nonlinear polarizability and (b) controlling molecular orientation at nanoscopic level. Intercalation compounds have potential because of the arrangements of the intercalated species are determined by the host-guest interactions $[163,164]$. 


\section{Photo-responsive intercalation compounds}

4.1 Photoinduced structural and morphological changes.

There are some examples on XRD-detectable nano-structural changes induced by photochemical reactions of the interlayer dyes. The change in the basal spacings triggered by the photoisomerization of the intercalated azobenzenes has been observed for organophilic smectites-nonionic azobenzene intercalation compounds[36, 37, 41, 147]. However, the location of the intercalated azobenzene is difficult to determine in those systems, since the dyes were solubilized in the hydrophobic interlayer spaces surrounded by alkylchains of the interlayer alkylammonium ions. Even after the careful control of the orientation of the intercalated amphiphilic cationic azobenzenes, photoresponse of the basal spacing has hardly been observed in clay-amphiphilic cationic azo dye systems[135-138]. Irreversible change in the basal spacing upon UV and visible light irradiations has been observed by using Li-fluor-taeniolite (cation exchange capacity (CEC): $1.57 \mathrm{meq} / \mathrm{g}$ ) and cationic azo dyes without flexible alkylchains in the structures [165].

When a cationic azo dye, $p$-[2-(2-hydroxyethyldimethylammonio)ethoxy]azobenzene bromide (Scheme 2c) was intercalated in magadiite with the adsorbed amount of $1.90 \mathrm{meq} / \mathrm{g}$ silicate), the basal spacing changed after UV irradiation from 2.69 to $2.75 \mathrm{~nm}$ and the value came back to $2.69 \mathrm{~nm}$ upon visible light irradiation (Fig. 6a)[42]. The reversible change in the basal spacing has been observed repeatedly as shown in XRD patterns of Fig. 6a. The spectral properties as well as XRD results revealed that the intercalated azo dye cations form head-to-head aggregates ( $H$-aggregate) in the interlayer space, as schematically shown in Fig. 6b. The fraction of cis-isomer at room temperature was ca.50 \%, which is lower than that (ca. 70\%) for the azo dye occulded in a mesoporous silica film[166, 167]. Upon UV irradiation, half of the trans-form isomerized to cis-form and co-exists with trans-form in a same interlayer space as suggested by the single phase X-ray diffraction patterns before and during the irradiation. First-order plot for the thermal cis-to-trans isomerization of the azo dye-magadiite at $360 \mathrm{~K}$ showed that the 
rate became slow after $20 \mathrm{~min}$.[168]. This fact suggests that the trans-azo dye cations are thought to form a densely-packed aggregate in the interlayer space. However, the cationic azo dye, which intercalated as $J$-aggregate (Fig. 6c) in the interlayer space of montmorillonite (CEC: $1.19 \mathrm{meq} / \mathrm{g}$ ), did not give the photoresponses of the basal spacing during the photoisomerization[169]. It is postulated that a densely packed aggregate is difficult to form in the interlayer space of magadiite at the photostationary state due to the geometric difference of the two isomers, and this causes the change in the basal spacings. As mentioned previously, amiphilic cationic azobenzene intercalated in layered silicates (smectites and magadiite) was photoisomerized while the basal spacing was hardly changed [136-138]. The cationic azo dye does not contain flexible units such as long alkylchains, therefore, the photoisomerization induced the change in the microstructure detectable by XRD. This demonstrated a type of photomechanical effect and larger volume change is expected.

Insert Figure 6.

XRD detectable microstructural change has also been observed in a cationic spyropyran-montmorillonite system[170]. As schematically shown in Figure 7, the introduction of a cationic spyropyran in montmorillonite has been conduced through two methods; cation-exchange reactions with interlayer $\mathrm{Na}$ ions of the host ("ion-exchange method") and partial exchange with pre-intercalated hexadecyltrimethylammonium $\left(\mathrm{C}_{16} 3 \mathrm{C}_{1} \mathrm{~N}^{+}\right)$ions ("guest-exchange method"). Reversible conversions of spyropyran-merocyanine were observed upon UV-Vis irradiation for both hybrids. The basal spacing changed reversibly by the photoinduced conversion in the absence of $\mathrm{C}_{16} 3 \mathrm{C}_{1} \mathrm{~N}^{+}$, while the basal spacing did not change in the latter case due to interlayer expansion by bulkier co-intercalated $\mathrm{C}_{16} 3 \mathrm{C}_{1} \mathrm{~N}^{+}$.

Insert Figure 7. 
Inoue and his coworkers have been reported the intercalation of a polyfluorinate cationic azo dye (C3F-Azo: Scheme 2d) into [171]a layered niobate[172] and a layered titanoniobate[173]. Bacause the intercalation of the azo dye into the niobate and titanoniobate is difficult, if compared with that into smectite, due to their higher layer charge densities, pre-intercalation of hexyamine and 1,1'-dimethyl-4,4'-bipyridinium and subsequent guest exchange with the C3F-Azo dye was conducted. The basal spacings of the niobate[174] and the titanoniobate intercalates (from (020) reflection) decreased by a light with shorter wavelength than $c a .370 \mathrm{~nm}$, and increased to the value same before the photoirradiations upon subsequent light irradiation at ca. $460 \mathrm{~nm}$. Reversible trans-to-cis photoisomerization of the intercalated azobenzene moiety accompanied the repeated changes in the basal spacings. The direction of the interlayer distance upon each isomerization was opposite to that observed in the magadiite system as described above.

Morphological change in the C3F-Azo-layered niobate hybrid film with response to light irradiation has been reported[175]. Right side of Figure 8 shows an AFM image of the C3F-Azo-layered niobate film, and the height profiles (along the white line perpendicular to the dashed line) are shown in the left side of this figure. After the irradiation of $c a .370 \mathrm{~nm}$ light, the bottom edge (point A in Figure 8) of the nanosheet stack slid out from the interior of the layered film, while the height of the top edge (point B) maintained. Subsequent higher wavelength light $(c a .460 \mathrm{~nm}$ ) irradiation resulted in the protruded bottom edge (point C) slid back to the original position before the photoirradiation. The sliding distance of the bottom edge of the film reached $c a .1500 \mathrm{~nm}$. The photoinduced nanosheet sliding back and forth on such a giant scale is interesting from the viewpoint of the driving mechanism in the morphological change. Photoresponsive morphological changes have also been reported in a hybrid film composed of an azobenzene containing polymer and a LDH obtained by using a layer-by-layer self-assembly (LbL) technique[176]. AFM observations of the resulting film exhibited changes in the surface roughness with responses to UV and visible light irradiation. 
Insert Figure 8.

\subsection{Photoinduced adsorption}

We have reported reversible change in the basal spacing by phenol adsorption triggered by photoirradiations. This was achieved by the complexation of smectite with the cationic azo dye, $p$-[2-(2-hydroxyethyldimethylammonio)ethoxy]azobenzene[177]. Phenol was intercalated montmorillonite (CEC: $1.19 \mathrm{meq} / \mathrm{g}$ clay) modified with the cationic azo dye to expand the interlayer space by mechanical mixing. From the change in the XRD pattern (Figure 9), photoinduced intercalation of phenol was observed by the UV irradiation, and subsequent visible light irradiation indicated phenol deintercalation. It was assumed to the intercalation and deintercalation of phenol induced by reversible trans-to-cis isomerization of the azobenzene chromophore. On the contrary, both of the intercalation and the photoinduced intercalation were not observed for the azo dye-Sumecton SA (the CEC of $0.71 \mathrm{meq} / \mathrm{g}$ clay). The dye orientation (with the molecular long axis inclined to the silicate layer) plays an important role in the photoinduced intercalation of phenol; the phenol intercalation before the irradiation is prerequiste to induce the photoresponsed intercalation[178]. Studies toward following goals are worth investigating; no intercalation at groud state, larger amount of intercalation by irradiation, complete deintercalation by subsequent irradition and effiencies of all the related phnomena.

Insert Figure 9.

We have deduced that photoisomerization to cis-form of azobenzene chromophore leads to the intercalation of atmospheric water[42] as well as phenol[177]. If azo dye without hydroxyl group is used, 
the interactions of water with intercalation compounds are expected to be weaker. In order to confirm the idea, another type of azo dye, 2-[4-(4-ethylphenylazo)phenoxy]ethyl(trimethyl)ammonium (Scheme 2e), was synthesized and intercalated into the intelayer space of smectite to compare the adsorptive properties the resulting intercalation compounds for phenol[179]. Due to the absence of the hydroxyl group, the hybrids are hydrophobic and the larger amount of phenol was intercalated before irradiation. Then, the amount of the intercalated phenol by the UV irradiation was smaller if compared when azodye with hydroxyl group.

Recently, molecular dynamics (MD) simulation of the layered silicates intercalating a series of cationic azo dyes has been investigated by Heinz and his coworkers[180]. The simulation results indicate that reversible change in the basal spacing upon UV and visible light irradiation may be improved through (1) presence of a co-intercalated species, (2) conformational rigidity of azo dye and (3) upright orientation of the dye. A moderate-to-high CEC, the absence of flexible alkyl spacers in the cationic azo dye, the use of rigid macrocyclic "pedestals" support this objective.

\subsection{Photoresponse of magnetic properties}

Magnetic properties of transition-metal layered hydroxides and double hydroxides have been investigated and the photoresponses of magnetic properties habe been reported. Such magnetism as ferromagnetism, ferrimagnetism, and antiferromagnetism depend on the interlayer distance[163, 181]. Fujita and Awaga reported the intercalation of an anionic dye, 8-((p-(phenylazo)phenyl)oxy-octanoate, into the interlayer space of $\left[\mathrm{Cu}_{2}(\mathrm{OH})_{3}\right]^{-}$and investigated the magnetic properties of the intercalation compound[182]. While the interlayer distance of the layered hydroxide was $2.07 \mathrm{~nm}$ in methanol, that in acetonitrile was increased to $3.87 \mathrm{~nm}$, which is almost twice as long as the molecular height of the 8-((p-(phenylazo)phenyl)oxy-octanoate anion, forming a membrane-like bilayer. Reversible mono-to-bilayer phase transition of the anion layer in the hybrid resulted in the drastic change in magnetic properties. The monolayer phase was paramagnetic down to $3 \mathrm{~K}$, while the bilayer phase became weak 
ferromagnet with critical temperature of $T_{\mathrm{c}}=10.8 \mathrm{~K}$. The origin of the magnetic variety was thought to be due to the sensitivity of the magnetic interactions to the $\mathrm{Cu}-\mathrm{OH}-\mathrm{Cu}$ bridging angles in the $\left[\mathrm{Cu}_{2}(\mathrm{OH})_{3}\right]^{-}$ network. Although the photoisomerization of azobenzene chromophore was not linked to the magnetic propertites [183], this is a successful example on controllable magnetic properties induced by using the structural change of the intercalation compounds.

Recently, Abellián et al. reported the photoresponses of magnetization and critical temperature $\left(T_{\mathrm{c}}\right)$ of ferromagnetic $\mathrm{Co}^{\mathrm{II}}-\mathrm{Al}^{\mathrm{III}}$-layered double hydroxide $(\mathrm{LDH})$ induced by trans-to-cis photoisomerization of the intercalated azobenzene dianion. The interlayer spacing changed reversibly by the isomerization. UV irradiation (trans-to-cis isomerization of the azobenzene chromophore) led to the increased $T_{\mathrm{c}}$ from 4.5 to 5.2 and the decreased magnetization (external magnetic field of $2 \mathrm{~T}$ at $2 \mathrm{~K}$ ) from 0.66 to $0.48 \mathrm{emu} / \mathrm{mol}$. The magnetic properties in $T_{\mathrm{c}}$ and magnetization came back to the values close to that obserbed before the $\mathrm{UV}$ irradiation. It was explained that the observed reversibility that antiferromagnetic dipoar interactions and magnetic correlation length with the aid of flexible LDH layers were concerned [184].

Reversible photoresponsive changes in magnetization have been achieved by hybridizing amphiphilic cationic azobenzene, montmorillonite and Prussian Blue (CN-Fe $\left.{ }^{\mathrm{II}}-\mathrm{NC}-\mathrm{Fe}^{\mathrm{II}}-\mathrm{O}\right)[185,186]$. A magnetic film has been fabricated through a Langmuir-Blodgett technique (azobenzene-clay film), cation-exchange reactions with $\mathrm{FeCl}_{2}$ and subsequent reactions with $\mathrm{K}_{3}\left[\mathrm{Fe}(\mathrm{CN})_{6}\right]$. Under an external magnetic field of $10 \mathrm{G}$, the hybrid multilayer films exhibited ferromagnetic properties with a critical temperature $\left(T_{\mathrm{c}}\right)$ of $3.2 \mathrm{~K}$. Upon repeated light irradiation of $\mathrm{UV}$ and Vis, the magnetization of the hybrid film at $2 \mathrm{~K}$ repeatedly decreased and increased, respectively, and the photoinduced changes were estimated to be $c a .11 \%$ in total. The change in the values has been explained by electrostatic field driven by the photoisomerization of the azobenzene chromophore. Such changes are necessary to transfer an electron from the $\left[\mathrm{Fe}(\mathrm{CN})_{6}\right]^{3-}$ to $\mathrm{Fe}^{\mathrm{III}}$, and this might affect the superexchange interaction between the spins in the Prussian Blue. In a separated paper, photoinduced electron-transfer from $\mathrm{Fe}^{\mathrm{II}}$ to $\mathrm{Co}^{\mathrm{III}}$ in a Co-Fe Prussian 
Blue-clay oriented film has been reported to vary the magnetization depending on the direction of the applied magnetic field [187].

Other photochromic dyes are also useful for controlled magnetic interactions between layers, because of reversible change in $\pi$-conjugated system in the dye assemblies. Kojima and his co-workers reported the intercalation of a photochromic diarylethene divalent anion into a layered cobalt(II) hydroxide, which contains both tetrahedrally and octahedrally coordinated cobalt(II) ions [188]. In the dark and under UV-irradiated (313 nm) conditions, open and closed forms of the interlayer diarylethene anion were obtained, respectively. The photochemical reactions forming closed form led to the change in Curie temperature from $T_{\mathrm{c}}=9$ to $20 \mathrm{~K}$. The enhancement has been explained by the delocalization of the $\pi$-electrons in the closed form, which correlates enhancement of the interlayer magnetic interactions.

Bénard et al. have investigated the intercalation of a cationic spyropyran into layered $\mathrm{MnPS}_{3}$ [189] and the variation of the magnetic properties in response to spyropyran-merocyanine conversion upon UV irradiation. Intercalation via cation exchange reactions into $\mathrm{MnPS}_{3}$ often results in the appearance of a spontaneous magnetization derived from generation of intralayer vacancies by losing $\mathrm{Mn}^{2+}$ ions. Upon repeating UV irradiation and thermal treatment, reversible change in the basal spacing by $0.01 \mathrm{~nm}$ was observed repeatedly in one of the film samples. The merocyanine form $(J$-aggregate $)$ was quite stable over several months in dark. While the critical temperature $\left(T_{\mathrm{c}}\right)$ did not change by the UV irradiation, remanence and coercitivity increased. After the subsequent thermal treatment, the VSM curves returned to the shape close to that before UV irradiation.

5. Photochromism based on photoinduced electron transfer

Viologens $\left(N, N^{\prime}\right.$-bis $(R)-4,4$ '-bipyridinium, or di $(R)$ viologen, Scheme 1e) are photoreduced reversibly in the presence of an electron donor to form blue radical cations, which is a kind of photochrmoic reaction between colorless to blue[190]. Structural variation of viologens using the organic moiety at 
4,4'-positions is a merit for the use as a building block of hybrid materials. The color development by electrochemical reduction and UV light irradiation is shown in Scheme 1e. Kakegawa et al. reported that some synthetic smectites (Sumecton SA, and Laponite XLG) play a role as an electron donor for the photoinduced reduction of the intercalated dimethylviologen[191]. Proposed electron donating sites are briding Si-O-Al (in a silicate layer of Sumecton SA), and crystal edges of smectites. From the aspect of designing adsorbents, dimethylviologen has been used as a scaffold to create nanospace in the interlayer spaces of smectites to accommodate 2,4-dichlorophenol[66, 192]. It was shown that charge-transfer interactions with dimethylviologen-smectites are a driving force for the adsorption.

Miyata et al. reported the photochromism of dipropyl and di- $n$-heptylviologens intercalated in the interlayer space of montmorillonite with co-intercalating poly(vinyl pyrrolidone) (PVP)[193]. The viologen dications were intercalated in the interlayer space of pre-synthesized montmorillonite-PVP intercalation compound by cation exchange. Photochemical studies were conducted out for cast films of viologen-montmorillonite-PVPs by the UV irradiation with Hg lamp. Upon UV irradiation, viologen radical cations formed as shown by blue color, characteristic absorption bands at 610 and $400 \mathrm{~nm}$ and ESR signal. Reversible color-development by UV irradiation and color-fading were observed. In this system, co-intercalated PVP was assumed to act as the electron donor for the reduction of the viologens. The color-fading required a longer period than that in a pure PVP matrix. Since the color-fading process in the PVP matrix was an oxidation caused by oxygen in air, the slow color-fading reaction observed for the viologen-montmorillonite-PVP system was explained by the prevention of contact between the viologen radical cations and the atmospheric oxygene.

Thompson and his coworkers have reported stable photoinduced charge separation in layered zirconium phosphonate containing viologen moiety in both powder and thin-film samples [194, 195]. In order to overcome the scattering problems associated with powder, transparent multilayer thin films of zirconium phosphonate viologen salt $(\mathrm{ZrPV}(\mathrm{X}))$ were grown directly onto fused silica substrates from 
aqueous solution. The sequential growth method has been applied in the preparation of $\mathrm{ZrPV}(\mathrm{X})$ films (Figure 10). In this case, fused-silica slides are treated with (et) $3 \mathrm{SiCH}_{2} \mathrm{CH}_{2} \mathrm{CH}_{2} \mathrm{NH}_{2}$, followed by treatment with $\mathrm{POCl}_{3}$. This procedure leads to a phosphonate-rich surface suitable for treatment with $\mathrm{ZrOCl}_{2}$. The slides are then allowed to react with $\mathrm{H}_{2} \mathrm{O}_{3} \mathrm{P}-\mathrm{CH}_{2} \mathrm{CH}_{2}$-bipyridinium- $\mathrm{CH}_{2} \mathrm{CH}_{2}-\mathrm{PO}_{3} \mathrm{H}_{2} \mathrm{X}_{2}$.

Insert Figure 10.

Photolysis of $\mathrm{Zr}\left(\mathrm{O}_{3} \mathrm{P}-\mathrm{CH}_{2} \mathrm{CH}_{2}\right.$ (bipyridinium) $\left.\mathrm{CH}_{2} \mathrm{CH}_{2}-\mathrm{PO}_{3}\right) \mathrm{X}_{2}(\mathrm{X}=\mathrm{Cl}, \mathrm{Br}, \mathrm{I}), \mathrm{ZrPV}(\mathrm{X})$, resulted in the formation of blue radical cations of viologen which are stable in air. The photoreduction of viologen in these thin-film samples was very efficient (quantum yields=0.15), showing simple isobestic behavior in the electronic spectra. Contrary to bulk solids, photoreduced thin films are very air sensitive. The mechanism for the formation of charge-separated states in these materials involves both irreversible and reversible components. An irreversible component is proposed to involve hydrogen atom abstraction by photochemically formed halide radicals, followed by structural rearrangements. Optimization of the reversible process may make it possible to use these materials for efficient conversion and storage of photochemical energy.

The photochromic behavior of dimethylviolgen intercalated into a series of layered transition metal oxides has been reported [196]. $\mathrm{K}_{2} \mathrm{Ti}_{4} \mathrm{O}_{9}$ [197], $\mathrm{HTiNbO}_{5}$ [198], $\mathrm{K}_{4} \mathrm{Nb}_{6} \mathrm{O}_{17}$ [199, 200], $\mathrm{HNb}_{3} \mathrm{O}_{8}$ [200], and $\mathrm{HA}_{2} \mathrm{Nb}_{3} \mathrm{O}_{10}(\mathrm{~A}=\mathrm{Ca}, \mathrm{Sr})$ [201], were used as host materials and dimethylviolgen was intercalated by cation exchange. The photochemical studies were conducted for powdered samples by irradiation with a $\mathrm{Hg}$ lamp, and the reactions were monitored by diffuse reflectance spectra. Semiconducting host layers acted as electron donors for the reduction of viologen to form radical cations of the intercalated dimethylviolgen in the interlayer space. The stability of the photochemically formed blue radical cations has been discussed with respect to their microscopic structures. 
The photochemistry of intercalation compounds formed between layered niobates $\mathrm{K}_{4} \mathrm{Nb}_{6} \mathrm{O}_{17}$ and $\mathrm{HNb}_{3} \mathrm{O}_{8}$ with dimethylviolgen can be controlled by changing the interlayer structures [200]. Two types of dimethylviolgenintercalated compounds with different structures have been prepared for each host. In the $\mathrm{K}_{4} \mathrm{Nb}_{6} \mathrm{O}_{17}$ system, two intercalation compounds were obtained by changing the reaction conditions. In both of the intercalation compounds, dimethylviolgen ions are located only in the interlayer $\mathrm{I} . \quad \mathrm{HNb}_{3} \mathrm{O}_{8}$ also gave two different intercalation compounds; one was prepared by the direct reaction of $\mathrm{HNb}_{3} \mathrm{O}_{8}$ with dimethylviolgen and the other was obtained by using propylammonium-exchanged $\mathrm{HNb}_{3} \mathrm{O}_{8}$ as an intermediate. In the latter compound, propylammonium ions and dimethylviolgen were located in the same layer. All the intercalation compounds formed dimethylviolgen radical cation in the interlayers by host-guest electron transfer upon UV irraiation. The presence of co-intercalated $\mathrm{K}^{+}$and propylammonium ion in the $\mathrm{K}_{4} \mathrm{Nb}_{6} \mathrm{O}_{17}$ and $\mathrm{HNb}_{3} \mathrm{O}_{8}$ systems, respectively, significantly affected the decay of the viologen radical cation. This difference was explained by guest-guest interactions with the co-intercalated photoinactive guests $\left(\mathrm{K}^{+}\right.$and propylammonium ion).

Viologens on a layered solids have also been used as electron mediator, the photoreduction of dipropyl and di- $n$-heptylviologens from incorporated PVP is an example [193]. Electron-transfer quenching of tris(2,2'-bipyridine)ruthenium(II) $\left(\left[\mathrm{Ru}(\mathrm{bpy})_{3}\right]^{2+}\right)$ by dimethylviologen in aqueous suspension of smectites (Sumecton SA, Laponite XLG, and ME-100) in the presence of PVP was also investigated [202]. It is known that dimethylviologen strongly interacts with clay surfaces $[191,203,204]$ and does not quench the excited state of $\left[\mathrm{Ru}(\mathrm{bpy})_{3}\right]^{2+}$ on clay due to segregation, which is a phenomenon occasionally observed for the intercalation as schematically shown in Figure 11 [205]. The concept has been proposed in 1980' [205] and more recently discussed in our recent review article [17]. On the contrary, the adsorption of PVP on clay resulted in the co-adsorption of $\left[\mathrm{Ru}(\mathrm{bpy})_{3}\right]^{2+}$ and dimethylviologen without segregation, and the photoluminescence study on the $\left[\mathrm{Ru}(\mathrm{bpy})_{3}\right]^{2+} /$ dimethylviologen in PVP-smectite indicated the homogeneous distribution of the adsorbed dyes without segregation. 
Insert Figure 11.

The intraparticle electron-transfer on smectite in the absence of PVP was revealed for the sysyem cotaining co-intercalation of dihexadecylviologen cation and tetraphenylporphine through hydrophobic interactions (Figure 12) [206]. Energy-transfer among naphtyl-, anthryl- and pyrenylalkylammonium bound to zirconium phosphate and photoinduced electron transfer from

5,10,15,20-tetrakis(4-phosphonophenyl)porphyrin to $N, N^{\prime}$-bis(3-phosphonopropyl)-4,4'-bipyridinium organized in $\mathrm{Zr}$ phosphonate based self-assembled multilayers have been reported [207-209]. The layered structure plays an important role in organizing reactants to control the reaction. Recently, Shinsuke Takagi and his co-workers estimated the size of aggregate (island) of a cationic porphine around $N, N^{\prime}$-bis(2,4-dinitrophenyl)viologen cations on Sumecton SA by using time-resolved fluorescent measurement [210]. The segregation structure was found to be different depending on the molecular structure of porphyrin and the island size is a key factor responsible for enhancing fluorescence quenching by electron transfer from viologen to porphyrin. The photoinduced electron transfer through interparticle electron hopping from $\left[\mathrm{Ru}(\mathrm{bpy})_{3}\right]^{2+}$-intercalated clays (Kunipia F, Sumecton SA, Laponite, and fluorohectorite) to the dimethylviologen counterparts in the presence of ethylenediamine tetraacetate (sacrificial electron donor) was shown by Nakato et al. [211]. The photo-reduction occured depending on the lateral size of the clay mineral particles; electron transfer was observed in the case of smaller sized clay minerals (synthetic saponite (Sumecton SA) and synthetic hectorite (Laponite)) with appropriate aggregation, while the electron transfer did not proceed in large clay mineral particles (natural montmorillonite and synthetic swelling mica) irrespective of the flocculation (Figure 13).

Insert Figures 12 and 13. 
Spatial separation of acceptor and donor species has been optimized to stabilize a long-lived charge-separated state as a result of suppresed back electron transfer [212]. $\mathrm{K}_{4} \mathrm{Nb}_{6} \mathrm{O}_{17}$ nanosheets are excited upon UV irradiation to generate electron-hole pairs, and then, dimethylviologen (divalent cation) adsorbed on hectorite nanosheets accepted photoexcited electrons from the niobate nanosheets. The stable photoinduced charge-separation has been explained by slower diffusion of the nanosheets that form the microdomains (Figure 14) than that of the molecular species. As a result, the generation of the radical cation was slower, followed by slow oxidation of the formed radical cation to the dication. Thus, the efficiency of the reduction and the sability of the formed charge separated states has been designed through the nanostructural design and the inter-particle level contolled spatial distribution of donor and acceptors in and on layered solids. Since the roles of viologens in photocataytic applications have long been recognized, the organization (and the characterization of them) of viologens achieved so far will bring useful information and hint to understand and modify the artificail photosynthteses based on layered solids [213].

Insert Figure 14.

\section{Conclusions and future perspectives}

Examples and progresses of photochromic reactions of intercalation compounds are summarized. Interactions of vairous photochromic dyes with layered solids have been investigated to control the photochrmoic reactions (selectivity, yield, and dynamics). The photochromic reaction of the interalated dyes have also been used to probe the microenvironments of interlayer space, to which conventional instrumental analyses are not useful. Not only the variation of layered materials but also possible chemical modification of the chemical nature of interlayer spaces makes the materials' diversity. Photoirradiation triggered responses of such properties of intercalation compouds as adsorptive and magnetic ones have 
successfully been achieved, which motivates further study on the photoresponsive functional intercalation compounds.

Developments regarding controlled solid-state forms of intercalation compounds from nano (nanoparticle with designed shape, size and size distribution) to macroscopic ones (large single crytals and oriented film) represent milestones for the application of photochromic intercalation compounds. No only for the solid-state, the structure of suspension (or disperion) of layered materials have been characterized and controlled, and possiblr role of the suspension for the controlled photochrmic reaction has been proposed. Combining the materials' diversity and the hierarchical control of the forms of intercalation compounds, the materials perfomances will be optimized further to lead future practical applications. The preparation of layered solids with novel structure and chemical nature, the modification of the interlayer space, and the complexation of newly developped photochrmoic dyes with appropriate layered solids will be conducted to find novel photoresponsive phenomena as well as to control photochromic reactions precisely. 
Figure Captions

Figure 1. Materials' variation in photochromic dyes to be intercalated into layered solids cited in the present review.

Figure 2. Surface modification of smectites with organoammonium ions.

Figure 3. (a) Absorption spectra of a clay-1 hybrid film recorded (1) before and (2) after UV irradiation, and (3) after subsequent visible light irradiation. The inserted photograph is the film after the UV irradiation. The left-half area was not exposed to the light using a black screen paper, (b) schematic drawing of proposed models of (top) clay-1 hybrid film, (bottom, left) intercalated $\mathbf{1}$ in the powder samples, (bottom, right) intercalated $\mathbf{1}$ in clay dispersed in the optically transparent film. (c) changes in the absorbance at $600 \mathrm{~nm}$ with alternative irradiation of UV and visible light: (squares) 1 in methanol, (circles) powder sample of the clay-1 hybrid, (triabgles) gelatin-clay-1 hybrid film.

Figure 4. (a) The temperature dependence of the fraction of the photochemically formed cis-isomer at the photostationary state for the $2 \mathrm{C}_{18} 2 \mathrm{C}_{1} \mathrm{~N}^{+}-\mathrm{TSM}$-azobenzene intercalation compound. Arrow indicates the phase transition temperature, (b) a photograph of experimental setup of recording absorption spectrum with UV and/or visible light irradiations under varied temperature using a cryostat.

Figure 5. (a) Posible photochemical reaction paths of stilbazolium. (b) A schematic drawing of the stilbazolium intercalated saponite. (c) Effect of $\mathrm{C}_{8} \mathrm{~N}^{+}$on photoreactivity of pre-intercalated $S$ type monomer on saponite; syn head-to-tail dimer (circle), syn head-to-head dimer (square) and $Z$ type monomer (triangle). Pre-intercalated stilbazolium-saponite was suspended in aqueous solution of $\mathrm{C}_{8} \mathrm{~N}^{+}$.

Figure 6. (a) The reversible change in the XRD pattern of the magadiite modified with p-[2-(2-hydroxyethyldimethylammonio)ethoxy]azobenzene. Inset in this figure shows the change in the basal spacing from the photochemical reactions. Schematic drawing of possible arrangements of the cationic azobenzene in layered silicates as (b) $H$ - and (c) $J$-aggregates. 
Figure 7. Schematic illustration of mechanism for the intercalation of the cationic spyropyran through the ionand guest-exchange methods in montmorillonite, followed by the conformational change in the spyropyran in the interlayer space upon the photoirradiations.

Figure 8. Change in the height profile of in the C3F-Azo-layered niobate hybrid film upon the repeated photoirradiations.

Figure 9. Change in the XRD patterns of p-[2-(2-hydroxyethyldimethylammonio)ethoxy]azobenzene-montmorillonite by the reaction with phenol and by photoirradiations. Photoinduced phenol intercalation behavior is also schematically summarized in this figure.

Figure 10. Proposed structure of $\mathrm{ZrPV}(\mathrm{X})$.

Figure 11. Variation of the spatial distribution of guest species in/on layered materials.

Figure 12. Schematic drawing of intraparticle electron transfer reactions from tetraphenylporphine to dihexadecylviologen in the interlayer space of smectite.

Figure 13. Schematic representation of the interparticle visible light-induced electron transfer from $\left[\mathrm{Ru}(\mathrm{bpy})_{3}\right]^{2+}$ - to dimethylviologen-clays.

Figure 14. Schematic illustration of spatial separation of acceptor (dimethylviologen on hectorite nanosheets) and donor (niobate nanosheets) to stabilize a long-lived charge-separated state. 


\section{Scheme Captions}

Scheme 1. Photochroism of representative photochromic dyes: (a) azobenzene, (b) spiropyrane, (c) diarylethene, (d) stilbazolium, and (e) viologens ( $N, N^{\prime}$-bis $(R)-4,4$ '-bipyridinium).

Scheme 2. Molecular structures of cationic azobenzene derivatives cited in this review. (a) $\pi$-( $\omega$-trimethylammoniodecyloxy)- $\pi$ '-(octyloxy)azobenzene, (b) $\pi$-( $\omega$-trimethylammonioheptyloxy)- $\pi$-(dodecyloxy)azobenzene, (c) $p$-[2-(2-hydroxyethyldimethylammonio)ethoxy]azobenzene, (d) [2-(2,2,3,3,4,4,4-heptafluorobutylamino)ethyl]-\{2-[4-(4-hexyphenylazo)-phenoxy]-ethyl $\}$ dimethylam monium, and (e) 2-[4-(4-ethylphenylazo)phenoxy]ethyl(trimethyl)ammonium. 


\section{Refereneces}

1. Anpo, M. Matsuura, T. (eds) (1989) Photochemistry on Solid Surfaces. Elsevier, Amsterdam

2. Anpo, M. (ed) (1996) Surface Photochemistry. Wiley Interscience, Chichester

3. Klafter, J. Drake, J. M. (eds) (1989) Molecular Dynamics in Restricted Geometries. Wiley Interscience, New York

4. Ramamurthy, V. (ed) (1991) Photochemistry in Organized \& Constrained Media. VCH Publishers Inc., New York

5. Ramamurthy, V. Schanze, K. S. (eds) (2000) Solid State and Surface Photochemistry. Marcel Dekker, New York

6. Fendler, J. H. (ed) (1994) Membrane-Mimetic Approach to Advanced Materials. Springer-Verlag Berlin Heidelberg

7. Alberti, G. Bein, T. (ed) (1996) Solid-State Supramolecular Chemistry: Two- and Three-Dimensional Inorganic Networks. Pergamon, Oxford

8. Thomas, J. K., (1987) J Phys Chem 91:267-276

9. Thomas, J. K., (1993) Chem Rev 93:301-320

10. Turro, N. J., Gratzel, M. Braun, A. M., (1980) Angew Chem Int Ed 19:675-696

11. Ramamurthy, V., (1986) Tetrahedron 42:5753-5839

12. Thomas, J. K., (1988) Acc Chem Res 21:275-280

13. Ogawa, M. Kuroda, K., (1995) Chem Rev 95:399-438

14. Ogawa, M., (1998) Annu Rep Prog Chem Sect, C: Phys Chem 94:209-257

15. Auerbach, S. M.,Carrado, K. A. Dutta, P. K. (eds) (2004) Handbook of Layered Materials. Taylor\&Francis, Boca Raton

16. Bergaya, F. Theng, B. K. G. Lagaly, G. (eds) (2006) Handbook of Clay Science. Elsevier Science, Amsterdam

17. Ogawa, M., Saito, K. Sohmiya, M., (2014) Dalton Transactions 43:10340-10354

18. Takagi, K. Shichi, T. (2000) In: Ramamurthy, V. Schanze, K. S. (eds) Photophysics and Photochemistry in Clay Materials. Solid State and Surface Photochemistry, 5, 2. Marcel Dekker, New York

19. Okada, T., Ide, Y. Ogawa, M., (2012) Chem Asian J 7:1980-1992

20. Takagi, S., Shimada, T., Ishida, Y., Fujimura, T., Masui, D., Tachibana, H., Eguchi, M. Inoue, H., (2013) Langmuir 29:2108-19

21. Whittingham, M. S. Jacobson, A. J. (eds) (1982) Intercalation Chemistry. Academic Press, New York

22. Müller-Warmuth, W. Schöllhorn, R. (eds) (1994) Progress in Intercalation Research. Kluwer Academic Publishers, Dordrecht

23. Inadomi, T., Ikeda, S., Okumura, Y., Kikuchi, H. Miyamoto, N., (2014) Macromol Rapid Commun

24. (ed) (1974) The Chemistry of Clay-Organic Reactions. John Wiley \& Sons Inc., London

25. Kaito, R., Miyamoto, N., Kuroda, K. Ogawa, M., (2002) J Mater Chem 12:3463-3468

26. Morrison, H. (ed) (1993) Biological Applications of Photochemical Switches. Wiley Interscience, New York

27. Crano, J. C., Guglielmetti, R. J. (eds) (1990) Main Photochromic Families. Organic Photochromic and Thermochromic Compounds 1. Prenum Press, New York

28. Crano, J. C., Guglielmetti, R. J. (eds) (1999) Physicochemical Studies, Biological Applications, and Thermochromism. Organic Photochromic and Thermochromic Compounds 2. Kluwer Academic / Prenum Publishers, New York

29. Dürr, H. Bouas-Laurent, H. (eds) (2003) Photochromism: Molecules and Systems. Elsevier, Amsterdam

30. Adams, J. M. Gabbutt, A. J., (1990) J Inclus Phenom Mol 9:63-83 
31. Irie, M.,Yokoyama, Y. Seki, T. (ed) (2013) New Frontiers in Photochromism. Springer, Japan

32. Takagi, K., Kurematsu, T. Sawaki, Y., (1991) J Chem Soc Perkin Trans 2 1517-1522

33. Sasai, R., Ogiso, H., Shindachi, I., Shichi, T. Takagi, K., (2000) Tetrahedron 56:6979-6984

34. Seki, T. Ichimura, K., (1990) Macromolecules 23:31-35

35. Tomioka, H. Itoh, T., (1991) J Chem Soc Chem Commun 532-533

36. Ogawa, M., Kimura, H., Kuroda, K. Kato, C., (1996) Clay Sci 10:57-65

37. Ogawa, M., Hama, M. Kuroda, K., (1999) Clay Miner 34:213-220

38. Sasaki, M. Fukuhara, T., (1997) Photochem Photobio 66:716-718

39. Kandori, H., Ichioka, T. Sasaki, M., (2002) Chem Phys Lett 354:251-255

40. Furutani, Y., Ido, K., Sasaki, M., Ogawa, M. Kandori, H., (2007) Angew Chem Int Ed 46:8010-2

41. Ogawa M., Fujii K., Kuroda K. Kato C. (1991) Mater Res Soc Symp Proc 233:89-94

42. Ogawa, M., Ishii, T., Miyamoto, N. Kuroda, K., (2001) Adv Mater 13:1107-+

43. Tran-Thi, T. H., Dagnelie, R., Crunaire, S. Nicole, L., (2011) Chem Soc Rev 40:621-39

44. Lebeau, B. Innocenzi, P., (2011) Chem Soc Rev 40:886-906

45. Naito, T., Kunishige, M., Yamashita, T., Horie, K. Mita, I., (1991) React Polym 15:185-192

46. Naito, T., Horie, K. Mita, I., (1993) Polym 34:4140-4145

47. Yoon, K. B. (2003) In: Auerbach, S. M.,Carrado, K. A. Dutta, P. K. (eds) Photoinduced Electron Transfer in Zeolites. Handbook of Zeolite Science and Technology, 13. CRC Press, New York

48. Yoon, K. B., (1993) Chem Rev 93:321-339

49. Hashimoto, S., (2003) J Photochem Photobio C: Photochem Rev 4:19-49

50. Ogawa, M., (2002) J Photochem Photobio C: Photochem Rev 3:129-146

51. Ogawa, M., Saito, K. Sohmiya, M., Eur J Inorg Chem in press

52. Oshita, S. Matsumoto, A., (2003) Chem Lett 32:712-713

53. Oaki, Y. Imai, H., (2009) Bull Chem Soc J 82:613-617

54. Guo, S., Sugawara-Narutaki, A., Okubo, T. Shimojima, A., (2013) J Mater Chem C 1:6989

55. Liu, N., Yu, K., Smarsly, B., Dunphy, D. R., Jiang, Y. B. Brinker, C. J., (2002) J Am Chem Soc 124:14540-1

56. Park, J., Yuan, D., Pham, K. T., Li, J. R., Yakovenko, A. Zhou, H. C., (2012) J Am Chem Soc 134:99-102

57. Yanai, N., Uemura, T., Inoue, M., Matsuda, R., Fukushima, T., Tsujimoto, M., Isoda, S. Kitagawa, S., (2012) J Am Chem Soc 134:4501-4

58. Grim, R. E. (1953) Clay Mineralogy. McGraw-Hill Book Company, New York

59. Van Olphen, H. (1977) An Introduction to Clay Colloid Chemistry 2nd Ed. Wiley Interscience, New York

60. Thompson, D. W. Butterworth, J. T., (1992) J Colloid Interface Sci 151:236-243

61. Ogawa, M., Nagafusa, Y., Kuroda, K. Kato, C., (1992) App Clay Sci 7:291-302

62. Kitajima, K. Daimon, N., (1974) Nippon Kagaku Kaishi 1:685

63. Soma, M., Tanaka, A., Seyama, H., Hayashi, S. Hayamizu, K., (1990) Clay Sci 8:1-8

64. Ogawa, M., Matsutomo, T. Okada, T., (2008) J Ceram Soc Jpn 116:1309-1313

65. Ogawa, M., Matsutomo, T. Okada, T., (2009) Bull Chem Soc J 82:408-412

66. Okada, T., Matsutomo, T. Ogawa, M., (2010) J Phys Chem C 114:539-545

67. Egawa, T., Watanabe, H., Fujimura, T., Ishida, Y., Yamato, M., Masui, D., Shimada, T., Tachibana, H., Yoshida, H., Inoue, H. Takagi, S., (2011) Langmuir 27:10722-10729

68. Barrer, R. M. (1978) Zeolites And Clay Minerals As Sorbents And Molecular Sieves. Academic Press, London

69. Mitchell, I. V. (ed) (1990) Pillared Layered Structures: Current Trends and Applications. Elsevier, London

70. Lagaly, G., (1981) Clay Miner 16:1-21 
71. Lagaly, G., (1986) Solid State Ion 22:43-51

72. Lagaly, G. Beneke, K., (1991) Colloid Polym Sci 269:1198-1211

73. Ogawa, M. Kuroda, K., (1997) Bull Chem Soc J 70:2593-2618

74. Okada, T. Ogawa, M., (2011) Clay Sci 15:103-110

75. Okada, T., Seki, Y. Ogawa, M., (2014) J Nanosci Nanotechnol 14:2121-2134

76. Lagaly, G., (1979) Adv Colloid Interface Sci 11:105-148

77. Schwieger, W. Lagaly, G. (2004) In: Auerbach, S. M.,Carrado, K. A. Dutta, P. K. (eds) Alkali Silicates and Crystalline Silicic Acids. Handbook of Layered Materials, 11. Taylor\&Francis, Boca Raton

78. Ide, Y., Ochi, N. Ogawa, M., (2011) Angew Chem Int Ed 50:654-656

79. Takahashi, N. Kuroda, K., (2011) J Mater Chem 21:14336-14353

80. Ruizhitzky, E. Rojo, J. M., (1980) Nature 287:28-30

81. Ruizhitzky, E., Rojo, J. M. Lagaly, G., (1985) Colloid Polym Sci 263:1025-1030

82. Ogawa, M., Okutomo, S. Kuroda, K., (1998) J Am Chem Soc 120:7361-7362

83. Ogawa, M., Miyoshi, M. Kuroda, K., (1998) Chem Mater 10:3787-+

84. Isoda, K., Kuroda, K. Ogawa, M., (2000) Chem Mater 12:1702-1707

85. Fujita, I., Kuroda, K. Ogawa, M., (2005) Chem Mater 17:3717-3722

86. Ide, Y., Fukuoka, A. Ogawa, M., (2007) Chem Mater 19:964-966

87. Ide, Y., Iwasaki, S. Ogawa, M., (2011) Langmuir 27:2522-2527

88. Nakamura, T. Ogawa, M., (2012) Langmuir 28:7505-7511

89. Clearfield, A. Constantino, U. (1996) In: Alberti, G. Bein, T. (eds) Layerd Metal Phosphates and Their Intercalation Chemistry. Solid-State Supramolecular Chemistry: Two- and Three-Dimensional Inorganic Networks., 7, 4. Pergamon, Oxford

90. Raveau, B., (1987) Rev Inorg Chem 9:37-64

91. Ide, Y., Sadakane, M., Sano, T. Ogawa, M., (2014) J Nanosci Nanotechnol 14:2135-2147

92. Kumar, C. V., Bhambhani, A. Hnatiuk, N. (2004) In: Auerbach, S. M.,Carrado, K. A. Dutta, P. K. (eds) Layered alpha-Zirconium Phosphates and Phosphonates. Handbook of Layered Materials, 7. Taylor\&Francis, Boca Raton

93. Alberti, G. (1996) In: Alberti, G. Bein, T. (eds) Layerd Metal Phosphonates and Covalently Pillared Diphosphonates. Solid-State Supramolecular Chemistry: Two- and Three-Dimensional Inorganic Networks., 7, 5. Pergamon, Oxford

94. Ogawa, M. Maeda, N., (1998) Clay Miner 33:643-650

95. Ogawa, M. Takizawa, Y., (1999) J Phys Chem B 103:5005-5009

96. Ogawa, M. Takizawa, Y., (1999) Chem Mater 11:30-+

97. Evans, D. G. Slade, R. C. T. (2006) In: Duan, X. Evans, D. G. (eds) Structural Aspects of Layered Double Hydroxides. Layered Double Hydroxides, Springer-Verlag, Heidelberg

98. Reichle, W. T., (1986) Chemtech 16:58-63

99. Trifirò, F. Vaccari, A. (1996) In: Alberti, G. Bein, T. (eds) Hydrotalcite-like Anionic Clays (Layered Double Hydroxides). Solid-State Supramolecular Chemistry: Two- and Three-Dimensional Inorganic Networks., 7, 8. Pergamon, Oxford

100. Rives, V. Ulibarri, M. A., (1999) Coordin Chem Rev 181:61-120

101. Li, F. Duan, X. (2006) In: Duan, X. Evans, D. G. (eds) Applications of Layered Double Hydroxides. Layered Double Hydroxides, Springer-Verlag, Heidelberg

102. Park, I. Y., Kuroda, K. Kato, C., (1990) J Chem Soc Dalton Trans 3071-3074

103. Chibwe, M. Pinnavaia, T. J., (1993) J Chem Soc Chem Commun 278-280

104. Ogawa, M. Inomata, K., (2011) Clay Sci 15:131-137

105. Li, L., Ma, R. Z., Ebina, Y., Iyi, N. Sasaki, T., (2005) Chem Mater 17:4386-4391

106. Liu, Z., Ma, R., Osada, M., Iyi, N., Ebina, Y., Takada, K. Sasaki, T., (2006) J Am Chem Soc 128:4872-80 
107. Kayano, M. Ogawa, M., (2006) Bull Chem Soc J 79:1988-1990

108. Arai, Y. Ogawa, M., (2009) Appl Clay Sci 42:601-604

109. Igarashi, S., Sato, S., Takashima, T. Ogawa, M., (2013) Ind Eng Chem Res 52:3329-3333

110. Ogawa, M., Morita, M., Igarashi, S. Sato, S., (2013) J Solid State Chem 206:9-13

111. Gabriel, J. C., Camerel, F., Lemaire, B. J., Desvaux, H., Davidson, P. Batail, P., (2001) Nature 413:504-8

112. Nakato, T., Furumi, Y. Okuhara, T., (1998) Chem Lett 611

113. Nakato, T. Miyamoto, N., (2002) J Mater Chem 12:1245-1246

114. Nakato, T., Miyamoto, N. Harada, A., (2004) Chemical Commun 78-9

115. Fossum, J. O., Gudding, E., Fonseca, D. D. M., Meheust, Y., DiMasi, E., Gog, T. Venkataraman, C., (2005) Energy 30:873-883

116. Fonseca, D. M., Meheust, Y., Fossum, J. O., Knudsen, K. D. Parmar, K. P., (2009) Phys Rev E Stat Nonlin Soft Matter Phys 79:021402

117. Ogawa, M., Takahashi, M., Kato, C. Kuroda, K., (1994) J Mater Chem 4:519-523

118. Isayama, M., Sakata, K. Kunitake, T., (1993) Chem Lett 1283-1286

119. Ogawa, M., (1998) Langmuir 14:6969-6973

120. Inukai, K., Hotta, Y., Taniguchi, M., Tomura, S. Yamagishi, A., (1994) J Chem Soc-Chem Commun 959-959

121. Hotta, Y., Taniguchi, M., Inukai, K. Yamagishi, A., (1997) Clay Miner 32:79-88

122. Suzuki, Y., Tenma, Y., Nishioka, Y. Kawamata, J., (2012) Chem Asian J 7:1170-1179

123. Kleinfeld, E. R. Ferguson, G. S., (1994) Science 265:370-373

124. Kleinfeld, E. R. Ferguson, G. S., (1996) Chem Mater 8:1575-+

125. Lvov, Y., Ariga, K., Ichinose, I. Kunitake, T., (1996) Langmuir 12:3038-3044

126. Keller, S. W., Kim, H. N. Mallouk, T. E., (1994) J Am Chem Soc 116:8817-8818

127. Sasaki, T., Watanabe, M., Hashizume, H., Yamada, H. Nakazawa, H., (1996) Chem Commun 229-230

128. Sasaki, T., Nakano, S., Yamauchi, S. Watanabe, M., (1997) Chem Mater 9:602-608

129. Lotsch, B. V. Ozin, G. A., (2008) Adv Mater 20:4079-+

130. Ariga, K., Ji, Q., McShane, M. J., Lvov, Y. M., Vinu, A. Hill, J. P., (2012) Chem Mater 24:728-737

131. Guang, C., Hong, H. G. Mallouk, T. E., (1992) Acc Chem Res 25:420-427

132. Sasaki, T., Watanabe, M., Hashizume, H., Yamada, H. Nakazawa, H., (1996) J Am Chem Soc 118:8329-8335

133. Osada, M. Sasaki, T., (2009) J Mater Chem 19:2503-2511

134. Osada, M. Sasaki, T., (2012) Adv Mater 24:210-228

135. Ogawa, M., (1996) Chem Mater 8:1347-\&

136. Ogawa, M. Ishikawa, A., (1998) J Mater Chem 8:463-467

137. Ogawa, M., Yamamoto, M. Kuroda, K., (2001) Clay Miner 36:263-266

138. Ogawa, M., Goto, R. Kakegawa, N., (2000) Clay Sci 11:231-241

139. Shimomura, M. Aiba, S., (1995) Langmuir 11:969-976

140. Iyi, N., Kurashima, K. Fujita, T., (2002) Chem Mater 14:583-589

141. Sudo, H., Hatano, B., Kadokawa, J. I. Tagaya, H., (2007) J Ceram Soc Jpn 115:901-904

142. Umemoto, T., Ohtani, Y., Tsukamoto, T., Shimada, T. Takagi, S., (2014) Chem Commun 50:314-6

143. Sasai, R., Shichi, T., Gekko, K. Takagi, K., (2000) Bull Chem Soc J 73:1925-1931

144. Sasai, R., Itoh, H., Shindachi, I., Shichi, T. Takagi, K., (2001) Chem Mater 13:2012-2016

145. Shindachi, I., Hanaki, H., Sasai, R., Shichi, T., Yui, T. Takagi, K., (2004) Chem Lett 33:1116-1117

146. Shindachi, I., Hanaki, H., Sasai, R., Shichi, T., Yui, T. Takagi, K., (2007) Res Chem Intermed 33:143-153

147. Fujita, T., Iyi, N. Klapyta, Z., (1998) Mater Res Bull 33:1693-1701 
148. Ahmadi, M. F. Rusling, J. F., (1995) Langmuir 11:94-100

149. Okahata, Y. Shimizu, A., (1989) Langmuir 5:954-959

150. Hu, N. F. Rusling, J. F., (1991) Anal Chem 63:2163-8

151. Takagi, K., Usami, H., Fukaya, H. Sawaki, Y., (1989) J Chem Soc Chem Commun 1174-1175

152. Usami, H., Takagi, K. Sawaki, Y., (1990) J Chem Soc Perkin Trans 2 1723-1728

153. Usami, H., Takagi, K. Sawaki, Y., (1992) J Chem Soc Faraday T 88:77-81

154. Usami, H., Takagi, K. Sawaki, Y., (1991) Bull Chem Soc J 64:3395-3401

155. Takagi, K., Shichi, T., Usami, H. Sawaki, Y., (1993) J Am Chem Soc 115:4339-4344

156. Shichi, T., Takagi, K. Sawaki, Y., (1996) Chem Lett 781-782

157. Shichi, T., Takagi, K. Sawaki, Y., (1996) Chem Commun 2027-2028

158. Moerner, W. E. (ed) (1988) Persistent spectral hole-burning : science and application. Springere-Verlarg, Berline

159. Sakoda, K. Kominami, K., (1993) Chem Phys Lett 216:270-274

160. Ogawa, M., Handa, T., Kuroda, K., Kato, C. Tani, T., (1992) J Phys Chem 96:8116-8119

161. Prasad, P. N. Karna, S. P., (1994) Int J Quant Chem 395-410

162. Munn, R. W. Ironside, C. N. (ed) (1993) Principles and Applications of Nonlinear Optical Materials. Springer Science + Business Nedia, B. V.,

163. Rabu, P. Drillon, M., (2003) Adv Eng Mater 5:189-210

164. Delahaye, É., Eyele-Mezui, S., Bardeau, J.-F., Leuvrey, C., Mager, L., Rabu, P. Rogez, G., (2009) J Mater Chem 19:6106

165. Iyi, N., Fujita, T., Yelamaggad, C. V. Arbeloa, F. L., (2001) Appl Clay Sci 19:47-58

166. Ogawa, M., Kuroda, K. Mori, J., (2000) Chem Commun 2441-2442

167. Ogawa, M., Kuroda, K. Mori, J., (2002) Langmuir 18:744-749

168. Ogawa, M., (2002) J Mater Chem 12:3304-3307

169. Ogawa, M., Ishii, T., Miyamoto, N. Kuroda, K., (2003) Appl Clay Sci 22:179-185

170. Kinashi, K., Kita, H., Misaki, M., Koshiba, Y., Ishida, K., Ueda, Y. Ishihara, M., (2009) Thin Solid Films 518:651-655

171. Yui, T., Yoshida, H., Tachibana, H., Tryk, D. A. Inoue, H., (2002) Langmuir 18:891-896

172. Tong, Z. W., Takagi, S., Shimada, T., Tachibana, H. Inoue, H., (2006) J Am Chem Soc 128:684-685

173. Tong, Z. W., Sasamoto, S., Shimada, T., Takagi, S., Tachibana, H., Zhang, X. B., Tryk, D. A. Inoue, H., (2008) J Mater Chem 18:4641-4645

174. Nabetani, Y., Takamura, H., Hayasaka, Y., Sasamoto, S., Tanamura, Y., Shimada, T., Masui, D., Takagi, S., Tachibana, H., Tong, Z. Inoue, H., (2013) Nanoscale 5:3182-93

175. Nabetani, Y., Takamura, H., Hayasaka, Y., Shimada, T., Takagi, S., Tachibana, H., Masui, D., Tong, Z. Inoue, H., (2011) J Am Chem Soc 133:17130-3

176. Han, J., Yan, D., Shi, W., Ma, J., Yan, H., Wei, M., Evans, D. G. Duan, X., (2010) J Phys Chem B 114:5678-85

177. Okada, T., Watanabea, Y. Ogawa, M., (2004) Chem Commun 320-321

178. Okada, T., Watanabe, Y. Ogawa, M., (2005) J Mater Chem 15:987-992

179. Okada, T., Sakai, H. Ogawa, M., (2008) Appl Clay Sci 40:187-192

180. Heinz, H., Vaia, R. A., Koerner, H. Farmer, B. L., (2008) Chem Mater 20:6444-6456

181. Hornick, C., Rabu, P. Drillon, M., (2000) Polyhedron 19:259-266

182. Fujita, W. Awaga, K., (1997) J Am Chem Soc 119:4563-4564

183. Fujita, W., Awaga, K. Yokoyama, T., (1999) Appl Clay Sci 15:281-303

184. Abellan, G., Coronado, E., Marti-Gastaldo, C., Ribera, A., Jorda, J. L. Garcia, H., (2014) Adv Mater 26:4156-62

185. Yamamoto, T., Umemura, Y., Sato, O. Einaga, Y., (2004) Chem Mater 16:1195-1201

186. Yamamoto, T., Umemura, Y., Sato, O. Einaga, Y., (2006) Sci Technol Adv Mater 7:134-138 
187. Yamamoto, T., Saso, N., Umemura, Y. Einaga, Y., (2009) J Am Chem Soc 131:13196-+

188. Shimizu, H., Okubo, M., Nakamoto, A., Enomoto, M. Kojima, N., (2006) Inorg Chem 45:2006

189. Benard, S., Leaustic, A., Riviere, E., Yu, P. Clement, R., (2001) Chem Mater 13:3709-3716

190. Monk, P. M. S. (1998) The Viologens: Physicochemical Properties, Synthesis and Applications of the Salts of 4,4'-Bipyridine. John Wiley \& Sons, Chichester

191. Kakegawa, N., Kondo, T. Ogawa, M., (2003) Langmuir 19:3578-3582

192. Okada, T. Ogawa, M., (2003) Chem Commun 1378-1379

193. Miyata, H., Sugahara, Y., Kuroda, K. Kato, C., (1987) J Chem Soc Farad T 1 83:1851-1858

194. Vermeulen, L. A. Thompson, M. E., (1992) Nature 358:656-658

195. Vermeulen, L. A., Snover, J. L., Sapochak, L. S. Thompson, M. E., (1993) J Am Chem Soc 115:11767-11774

196. Nakato, T. Kuroda, K., (1995) Eur J Sol State Inor 32:809-818

197. Miyata, H., Sugahara, Y., Kuroda, K. Kato, C., (1988) J Chem Soc Farad T 1 84:2677-2682

198. Nakato, T., Miyata, H., Kuroda, K. Kato, C., (1988) React Solids 6:231-238

199. Nakato, T., Kuroda, K. Kato, C., (1989) J Chem Soc Chem Commun 1144-1145

200. Nakato, T., Kuroda, K. Kato, C., (1992) Chem Mater 4:128-132

201. Nakato, T., Ito, K., Kuroda, K. Kato, C., (1993) Microporous Materials 1:283-286

202. Kakegawa, N. Ogawa, M., (2004) Langmuir 20:7004-7009

203. Weber, J. B., Perry, P. W. Upchurch, R. P., (1965) Soil Sci Soc Am J 29:678-688

204. Raupach, M., Emerson, W. W. Slade, P. G., (1979) J Colloid Interface Sci 69:398

205. Ghosh, P. K. Bard, A. J., (1984) J Phys Chem 88:5519-5526

206. Kakegawa, N. Ogawa, M., (2003) Clay Sci 12:153-158

207. Snover, J. L. Thompson, M. E., (1994) J Am Chem Soc 116:765-766

208. Ungashe, S. B., Wilson, W. L., Katz, H. E., Scheller, G. R. Putvinski, T. M., (1992) J Am Chem Soc 114:8717-8719

209. Kumar, C. V. Chaudhari, A., (1994) J Am Chem Soc 116:403-404

210. Konno, S., Fujimura, T., Otani, Y., Shimada, T., Inoue, H. Takagi, S., (2014) J Phys Chem C 118:20504-20510

211. Nakato, T., Watanabe, S., Kamijo, Y. Nono, Y., (2012) J Phys Chem C 116:8562-8570

212. Miyamoto, N., Yamada, Y., Koizumi, S. Nakato, T., (2007) Angew Chem Int Ed 46:4123-7

213. Abe, R., Shinmei, K., Koumura, N., Hara, K. Ohtani, B., (2013) J Am Chem Soc 135:16872-84 